\title{
Türkiye Buğday Sektörünün Eşanlı Model Yöntemiyle Tahmini
}

\author{
Ali DÖRTOK ${ }^{1}$ iD , Adem AKSOY ${ }^{\circ}$ iD \\ ${ }^{1}$ Türkiye İstatistik Kurumu Kayseri Bölge Müdürlüğü, ${ }^{2}$ Atatürk Üniversitesi Ziraat Fakültesi Tarım Ekonomisi Bölümü \\ $\square$ :aaksoy@atauni.edu.tr
}

\section{ÖZET}

Buğday, ülkelerin temel ihtiyaçlarından biri olan ve insanların gıda ihtiyacını gideren önemli bir tarım ürünüdür. Türkiye ve dünya ekonomisinde önemli bir paya sahip olmasından dolayı buğday arz ve talep oluşumu ile dış ticaret dinamiklerinin bilinmesi önem arz etmektedir. Bu çalışmanın amacı buğday ürünün arz, talep, dış ticaret ve fiyat boyutunun 1961 ile 2013 yılları arasında eşanlı bir sistem içerisinde modellenmesidir. $\mathrm{Bu}$ amaçla eşanlı model tahmin yöntemlerinden Genelleştirilmiş Momentler yöntemi ile model tahmini gerçekleştirilmiştir. Buğday; üretimini etkileyen değişkenler bir önceki yıl buğday üretim miktarı, buğday ve mısır üretici fiyatı ile TMO alım miktarı, tüketimini etkileyen değişkenler buğday fiyatı ve kişi başı gelir, ithalatını etkileyen değişkenler üretimin tüketimi karşılama oranı ve stoklar, ihracatını etkileyen değişkenler ise buğday üretimi, stok ve dolar kuru, fiyatı etkileyen değişkenler ise stok, gübre fiyatı ve ihracat olarak bulunmuştur.
DOI:10.18016/ksudobil. 391087

\section{Makale Tarihçesi}

Geliş Tarihi : 06.02.2018

Kabul tarihi : 12.03 .2018

\section{Anahtar Kelimeler}

Buğday, eşanlı model, GMM,

Türkiye

\section{Araştırma Makalesi}

\section{Estimation Model With Simultaneous Process of Turkey's Wheat Industry}

\begin{abstract}
Wheat is an important agricultural product supplying the needs of food and nutrition of people concequentelly, basic needs of countries. Knowing dynamics of foreign trade and also formation of supply and demand of wheat is important since it has an important share in the world as well as Turkish economy. The aim of this study was to model the dimension of supply, demand, foreign trade and price of wheat by using a simultaneous system between 1961 and 2013. For this purpose, Generalized Moments Method as simultaneous estimation method has been estimated. In this study, the variables affecting the wheat production were the amount of wheat production in prior year, the producer price of wheat and corn, and the amount of product bought by TMO. Whereas, the variables affecting consumption were wheat prices and income per capita. The variables affecting export were decided to be wheat production, stock and exchange rate of dollar. The variables affecting import were found as rate of production meeting consumption and stocks, and lastly variables affecting price were presented as amount of stocks, fertilizer price and export.
\end{abstract}

\section{Article History}

Geliş : 06.02.2018

Kabul : 12.03 .2018

\author{
Keywords \\ Wheat, \\ simultaneous model, \\ GMM, \\ Turkey
}

\section{Research Article}

To Cite : Dörtok A, Aksoy A 2018. Türkiye Buğday Sektörünün Eşanlı Model Yöntemiyle Tahmini. KSÜ Tarım ve Doğa Derg 21(4):580-586, DOI:10.18016/ksudobil.391087

\section{GIRIŞ}

Dünya ve Türkiye'nin çoğu yerinde üretimi yapılan buğday; gerek çok büyük üretici kitlesini ilgilendirmesi, gerekse insanların temel gıdası olan ekmeğin hammaddesini oluşturması bakımından oldukça önemli bir üründür. Buğday sektörünün önemi, artan nüfus ve azalan tarım alanlarının ortak etkileri sonucu olarak artarak devam etmektedir. Buğday, Türkiye tarımındaki yeri ve önemi itibariyle stratejik bir tarım ürünüdür.

Buğday (Triticumspp) bütün dünyada ıslahı yapılmış, tek yıllık otsu bir bitkidir. İnsan beslenmesinde kullanılan kültür bitkileri arasında Türkiye'de olduğu gibi dünyada da ekiliş ve üretim bakımından ilk sırada yer almaktadır (Akay, 2005). Bunun sebeplerden birisi buğday bitkisinin geniş bir adaptasyon yeteneğine sahip olmasıdır. Çok sayıda çeşide sahip olması nedeniyle, dünyanın hemen her tarafında 
yetiştirilmektedir. Ayrıca buğday danesi uygun besleme değeri, saklama ve işlenmesindeki kolaylıklar nedeniyle yaklaşık olarak 50 ülkenin temel besini durumundadır. Buğday, dünya nüfusuna bitkisel kaynaklı besinlerden sağlanan toplam kalorinin yaklaşık \%20'sini sağlamakta, başta unlu mamuller olmak üzere birçok gıda ve sanayi sektöründe kullanılmaktadır (Özcan ve ark.,2009).

Bir ülkenin gelişmişlik düzeyi hangi seviyede olursa olsun buğday üretiminde mutlak suretle kendine yeterli olması önemlidir. Geçmişte yaşanan savaş ve kıtlık dönemleri zorunlu gida maddesi buğday olan ülkeler için buğdayın ne kadar vazgeçilmez bir ürün olduğunu göstermiştir. Bir ülke ekonomik olarak ne kadar güçlü olursa olsun vatandaşlarının ihtiyacı olan buğdayı üretemiyorsa, başka ülkelere her zaman muhtaç yaşamak zorundadır (Akay, 2005).

Başta Avrupa, Kuzey Amerika ve Yakın Doğu olmak üzere Dünya'daki insanların büyük çoğunluğunun ana besin kaynağını buğday oluşturmaktadır. Tahıllar yüksek ekonomik önemleri nedeniyle üzerine en çok çalışılan bitkilerin başında gelmektedir. Bunun sonucunda çok değişik çevre koşullarına uyum sağlayabilecek çeşitler ve 37 genotipler geliştirilmiştir. İşte tahıllar gösterdikleri bu çeşit ve form zenginliği nedeniyle Dünya'da en fazla yayginlık gösteren bitki grubudur (Sepetoğlu, 2006).

Buğday üretimi, dünyada ekonomik ve stratejik bir öneme sahiptir. Buğday; binlerce yıl beslenmenin temeli olmuş, toplumda kendine güvenin ve istikrarın esasını teşkil etmiştir. Türkiye'de üretimi yapılan bitkisel ürünler içinde en büyük pay ve öneme sahip olan üründür. Buğday insanların ve hayvanların ihtiyacını karşılayan gıda maddesidir. Buğdayın tüketimi ülkelerin nüfuslarına göre değişmekle beraber gelişmekte olan ve geri kalmış ülkelerde temel besin maddesi olan ekmeğin ham maddesini oluşturması açısından büyük önem taşımaktadır (Oğuz ve Arısoy, 2005).

Türkiye'de buğday büyük ölçüde kurak iklim koşullarında yapıldığı için verimi düşük ve dolayısıyla buğday üreticisinin geliri de diğer ürünlere göre daha az olmaktadır. Ayrıca bazı bölgelerde yaşanan iklim koşullarından dolayı buğdaydan başka bir ürün üretimi yapmak mantıklı değildir (Aykanat, 2009). Türkiye'de vatandaşların zorunlu gıda maddesi

$$
\begin{aligned}
& B \ddot{\mathrm{U}}_{t}=\alpha_{0}+\alpha_{1} B F_{t-1}+\alpha_{2} B \ddot{\mathrm{U}}_{t-1}+\alpha_{3} T M O_{t}+\alpha_{4} M F_{t-1}+\alpha_{5} D_{t}+e_{1 t} \\
& K B T_{t}=\beta_{0}+\beta_{1} B F_{t}+\beta_{2} K G_{t}+e_{2 t} \\
& I H R_{t}=\theta_{0}+\theta_{1} B \ddot{\mathrm{U}}_{t}+\theta_{2} S T O K_{t}+\theta_{3} K U R_{t}+e_{3 t} \\
& I T H_{t}=\delta_{0}+\delta_{1} \mathrm{U}_{t}+\delta_{2} S T O K_{t}+e_{4 t} \\
& B F_{t}=\gamma_{0}+\gamma_{1} S T O K_{t}+\gamma_{2} G \dot{\mathrm{I}} F_{t}+\gamma_{3} I H R_{t}+e_{5 t}
\end{aligned}
$$

Burada (1) numaralı model, Nerlove (1956) tarafindan önerilen arz modeli genişletilerek oluşturulan buğday arz modeli olup, $B$ Ü, buğday üretim miktarını (bin ton); olmasından dolayı buğday üretimin garanti altına alınması gerekmektedir. Türkiye'de buğday sektörünü bütün olarak ele alan az sayıda çalışmaya rastlanmıştır. Adanacioğlu ve Engindeniz (2011), ğday sektöründe üretimde etkili olan faktörlerin analitik yaklaşımla incelemişlerdir. Demir (2012), egilimini bölgeler düzeyinde incelemiştir. Dawson çeyrek dönemlik panel verileri kullanılarak buğday ihracatının ihracat birim değerleri ile döviz kuru arasındaki ilişki incelenmiştir.

Buğday sektörü ile ilgili uygun politikaların oluşturulmasına katkıda bulunacak bir çalışmanın gerekliliği ile gerçekleştirilen böyle bir çalışma ile mevcut boşluğun dolduracağına inanılmaktadır. $\mathrm{Bu}$ bağlamda çalışmanın amacı buğday ürününün arz, alep, dış ticaret ve fiyat boyutunun 1961 ile 2013 arasında eşanlı bir sistem içerisinde yöntemleri yardımıyla modellerin tahmin edilmesi

\section{MATERYAL ve METOT}

Çalışmada modellerin tahmin edilmesine temel teşkil edecek veriler Birleşmiş Milletler Gida ve Tarım Örgütü (Food and Agriculture Organisation - FAO) veri tabanından elde edilmiştir. Veri seti olarak tek bir kaynağın tercih edilmesinin nedeni verilerin hem değişkenler arasında ve hem de zaman boyutunda dirbirleriyle tutarlılık sağlamasıdır. Modellere dahil ecek değişken sayısını en üst düzeyde tutabilmek buğday sektörüne etkisi olabilecek tüm değişkenler

Metot

Çalışmada buğday ürünün arz, talep, fiyat ve diş ticaret boyutunu incelemek amacıyla eşanlılık ilişkisini gösteren üretim, tüketim, ithalat, ihracat, fiyatlar olmak üzere 5 farklı model kurgulanmıştır.

$B F$, sabit fiyatlarla buğdayda çiftçinin eline geçen fiyat $^{1}$ (ABD doları/bin ton); TMO, Toprak Mahsülleri Ofisi alım miktarını (bin ton); $M F$, sabit fiyatlarla 
mısır çiftçinin eline geçen fiyatı ${ }^{1}$ (ABD doları/bin ton); $D, 1975$ yılında buğday üretimindeki yapısal kırılmayı temsil eden kukla değişkeni göstermektedir. $\mathrm{Bu}$ modelde birçok değişken (üretici birim fiyatları (cari ve tl olarak), tüketici fiyatları (ekmek, makarna fiyatı vb.), alternatif ürün fiyatı (arpa üretici birim fiyatı), (enflasyon, nüfus, verim, ekilen alan, sıcaklık, yağış miktarı, traktör ve biçer döver sayısı vb.) buğday fiyatı, üretimi ve ikame ürün fiyatı önceki yıllara olan bağıntısı 6'ya kadar model kapsamında değerlendirilmiştir. Denenen değişkenler istatistiksel anlamlılık ile iktisadi beklentiye uygun işaret kapsamında seçilmiş̧tir.

(2) numaralı model buğday klasik talep modeli olup $K B T$, kişi başı buğday tüketimini ${ }^{2}$ (bin ton/bin kişi); $B F$, sabit fiyatlarla buğdayda çiftçinin eline geçen fiyatı (ABD doları/bin ton); $K G$, sabit fiyatlarla kişi başı Gayri Safi Yurtiçi Hasılayı (ABD doları) temsil etmektedir. Bu modelde birçok değişken (üretici birim fiyatları (cari ve TL olarak), tüketici fiyatları (ekmek, makarna fiyatı vb.), alternatif ürün fiyatı (mısır ve arpa üretici birim fiyatı), enflasyon, nüfus) model kapsamında değerlendirilmiştir. Denenen değişkenler istatistiksel anlamlılık ile iktisadi beklentiye uygun işaret kapsamında seçilmiştir.

(3) numaralı model buğday ihracat modeli olup $I H R$, buğday ihracat miktarın (bin ton); BÜ, buğday üretim miktarını (bin ton); STOK, buğday stok miktarını (bin ton); KUR, dolar kurunu (TL) göstermektedir. Birçok değişken (ihracat birim fiyatları, ihracat birim fiyatlarının çiftçinin eline geçen fiyata oranları, dünya buğday fiyatı, dünya buğday üretimi vb.) model kapsamında değerlendirilmiştir. Denenen değişkenler istatistiksel anlamlılık ile iktisadi beklentiye uygun işaret kapsamında seçilmiştir.

(4) numaralı model buğday ithalat modeli olup ITH, buğday ithalat miktarını (bin ton); ÜT, buğday üretiminin tüketimini karşlama oranını; STOK, buğday stok miktarını (bin ton) göstermektedir. Birçok değişken (ithalat birim fiyatları, ithalat birim fiyatlarının çiftçinin eline geçen fiyata oranları, dünya buğday fiyatı, dünya buğday üretimi vb.) model kapsamında değerlendirilmiştir. Denenen değişkenler istatistiksel anlamlılık ile iktisadi beklentiye uygun işaret kapsamında seçilmiştir.

(5) numaralı model buğday fiyat modeli olup $B F$, sabit fiyatlarla buğdayda çiftçinin eline geçen fiyatı (ABD doları/bin ton) ,STOK, buğday stok miktarını (bin ton); $G \dot{I} F$, gübre ithal birim fiyatını ${ }^{3} ; H R$, buğday ihracat miktarını (bin ton) temsil etmektedir. Birçok değişken ekilen alan, üretim, dünya buğday fiyatı, TMO alım fiyatı, kişi başı gelir, ithalat, ihracat, verim vb. model

${ }^{1}$ Ürün birim fiyatları, FAO veri tabanından elde edilen fiyattan arındırılmış üretim değeri kullanılarak yazar tarafından hesaplanmıștır.

${ }^{2}$ Tüketim olarak gıda amaçlı buğday tüketimi dikkate alınmıştır. Tohum, yem ve diğer (sabun yapımı vb.) amaçlar için kullanılan buğday tüketimi dahil edilmemiştir. kapsamında değerlendirilmiştir. Denenen değişkenler istatistiksel anlamlılık ile iktisadi beklentiye uygun işaret kapsamında seçilmiş̧ir.

$\mathrm{t}$, zaman indeksini; $\alpha, \beta, \theta, \delta$ ve $\gamma$ tahmin edilecek parametreler, $e_{1}, e_{2}, e_{3}, e_{4}$ ve $e_{5}$ hata terimlerini göstermektedir.

Bu çalışmada tahmin edilen modeller (1) - (5)'den görüldüğü üzere eşanlı olarak tahmin edilmiştir. Literatürde birçok eşanlı model tahmin yöntemi bulunmaktadır. Genelleştirilmiş Momentler Metodu yöntemleri ile model tahmini gerçekleştirilmiştir. Model tahminleri Stata12.0 ekonometrik paket programı ile gerçekleştirilmiştir.

$\mathrm{Bu}$ tür çalışmalarda yöntem olarak GİR, DEKK, 2EKK, 3-EKK ve GMM kullanılmakta olup eşanlı denklem sisteminin tahmin edilmesi için literatür tarafından çok fazla yöntem önerilmesine rağmen her bir yöntem farklı bir ekonometrik problemin varlığ halinde tercih edilmektedir. Bu çalışmada yukarıda ismi geçen yöntemlerin hepsi denenmiş olup aşağıdaki avantajlarından dolayı çalışmada GMM yöntemi kullanılmıştır. $\mathrm{Bu}$ avantajlar özetlenecek olunursa; ilgili yöntem hem modeller arası hataların ilişkili yapısına izin verirken, hem de içsel değişkenlerin meydana getirdiği yanlılık problemini dikkate alarak otokorelasyona karşı güçlü standart hatalar üretmesine imkan vermiştir. Dolayısıyla bu yöntem bahsedilen tüm bu ekonometrik problemleri çözerek modellerin eşanlı olarak tahmin edilmesini sağlamıştır. Böylece bu çalışmada hangi eşanlı model tahmin yönteminin hangi problemlere sahip olduğu ve bu problemlerin nasıl çözüleceği gösterilerek eşanlı model tahmini literatürüne uygulama anlaminda katkı sağlanmaya çalışılmıştır.

\section{BULGULAR VE TARTISMA}

\section{Durağanlık testleri}

Çalışmada kullanılan veriler zaman serisi olduklarindan tahmin edilecek ekonometrik modellerin de zaman serisi tahmin problemlerini taşıması muhtemel olacaktır. $\mathrm{Bu}$ problemlerden en önemlisi değişkenlerin durağan olup olmamasıdır. Bu bağlamda, zayıf durağanlık kabaca ifade edilecek olunursa, zaman boyunca ilgili serinin ortalaması ve varyansının değişmemesidir. Eğer modelde yer alan değişkenler durağan olmazsa sahte regresyon ortaya çıkacaktır. $\mathrm{Bu}$ durum parametre tahminlerinin anlamlılık sinamalarını gösteren $t$ istatistiklerinin ve açıklayıcılık katsayısının olduğundan yüksek çıkmasına sebebiyet verecektir.

Ekonometrik modellerde kullanılacak değişkenlerin

${ }^{3} \mathrm{FAO}$ veri tabanından elde edilen gübre dış ticaret verileri kullanılarak yazar tarafindan hesaplanmıştır. 
durağanlık sınaması literatürde yaygın olarak kullanılan birim kök testleri ile gerçekleştirilmiş ve sonuçlar Çizelge 1'de verilmiştir.

Bir zaman serisinin veri üretim sürecine bağlı olarak birim kök test sınamasını etkileyen birçok faktör (örneğin yapısal kırılmalar, gecikme sayıları, deterministik terimler vb.) olduğundan bu çalışmada ilgili serilerin durağanlığı araştırılırken literatür tarafından önerilen birden çok birim kök testinden faydalanılmıştır. Çizelge 1'de ise yapısal kırılmayı dikkate alan bir birim kök testinin sonuçları raporlanmıştır.

Literatürde genişletilmiş Dickey ve Fuller (1979) birim kök testi halen uygulanmakta olan bir test olsa da beraberinde bazı sorunları getirmektedir. Zaman serisi değişkeni, analiz döneminin çeşitli alt bölümlerinde deterministik trend etrafında durağan özelliğe sahip olabilir. Diğer bir ifadeyle ekonomideki şoklar, geleneksel birim kök süreci görüşüne karşın geçici şoklardır ve zaman serisi bu şokların ardından normal trend seviyesine dönmektedir. $\mathrm{Bu}$ yüzden yapısal kırılmayı dikkate almayan birim kök testlerinde, birim kök yokluk hipotezi yanlış iken kabul edilmesi olasılığı artmaktadır. Bu da testin gücünü azaltmaktadır. Bu durum Perron (1989) çalışmasında ele alınmış ve trend fonksiyonunda bir defalık kırılma meydana gelmesi halinde uygulanan Dickey ve Fuller (1979) birim kök testinin gerçekte yanlış olan birim kök yokluk hipotezini reddetmede başarısız olduğu gösterilmiştir. Perron (1989) çalışmasında kırılma zamanı dışsal (önceden bilinen bir tarih) olarak belirlenmektedir. Ancak bu durum literatürde eleştirilmiş ve kırılma zamanının içsel olarak belirlenmesi gerektiği belirtilmiştir. Bunun sonucu olarak literatürde kırılma zamanının içsel olarak belirlendiği farklı test prosedürleri (Zivot ve Andrews (1992) ve Perron (1997)) geliştirilmiştir. Bu çalışmalara göre geleneksel birim kök testlerindeki aykırı değerlerden kaynaklanan yanlılık, kırılma zamanının içsel olarak belirlenmesi durumunda giderilmektedir. Ayrıca kırılma zamanının içsel olarak belirlenmesinin bir diğer avantajı da zaman serisine önyargısız bir yaklaşım ile kırılma olup olmadığının test edilebilmesidir.

$\mathrm{Bu}$ kapsamda yapısal kırılmayı dikkate alan ve kırılmanın içsel olarak (her bir dönemin muhtemel kırılma olarak istatistiksel anlamlılığa tabi tutularak) belirlendiği Zivot ve Andrews (1992) tarafindan önerilen ZA testi ilgili serilere uygulanmış ve sonuçları Çizelge 1'de sunulmuştur. Kırılma hem serinin seviyesinde hem de eğiliminde olacak şekilde dikkate alınmıştır. Gecikme sayısı ise Bayes Bilgi Kriterine göre belirlenmiştir.

Çizelge 1'deki sonuçlara göre kişi başı tüketim ve kişi başı gelir serileri dışındaki seriler en az \%10 önem seviyesinde yapısal kırılmalar ile birlikte durağan bulunmuştur. Nihai olarak modeller tahmin edilirken kişi başı tüketim ile kişi başı gelir değişkenleri durağan-dışı kabul edilirken diğer seriler durağan olarak dikkate alınmıştır.

Çizelge 1. Zivot-Andrews yapısal kırılmalı birim kök testi sonuçları

\begin{tabular}{|c|c|c|c|}
\hline \multirow{2}{*}{ SERİLER } & \multicolumn{3}{|l|}{$\mathrm{ZA}$} \\
\hline & t-istatistiği & kırılma yılı & gecikme \\
\hline üretim & $-5.727^{b}$ & 1975 & 1 \\
\hline buğday fiyat & $-4.991^{c}$ & 1986 & 0 \\
\hline tmo alım miktarı & $-6.390^{\mathrm{a}}$ & 1994 & 1 \\
\hline misır fiyatı & $-6.458^{a}$ & 1995 & 0 \\
\hline tüketim & -3.535 & 1991 & 1 \\
\hline gelir & -4.139 & 2004 & 0 \\
\hline ithalat & $-5.458^{b}$ & 2004 & 0 \\
\hline ihracat & $-5.793^{a}$ & 1991 & 0 \\
\hline üretim/tüketim & $-5.585^{a}$ & 1983 & 0 \\
\hline stok & $-7.650^{a}$ & 2001 & 0 \\
\hline kur & $-5.017 \mathrm{c}$ & 2000 & 1 \\
\hline gübre fiyatı & $-5.718^{a}$ & 2001 & 0 \\
\hline
\end{tabular}

Notlar: (1): a,b,c; sırasıyla ilgili test istatistiğinin \%1, \%5 ve \%10 önem seviyesinde ret edildiğini göstermektedir.

\section{Model tahmini}

Modeller eşanlı bir denklem sisteminden oluştuğundan tahminler de literatür tarafindan önerilen eşanlı denklem tahmin yöntemleri ile gerçekleştirilmelidir. Bu yöntemler GİR, DEKK, 2EKK, 3-EKK ve GMM olarak özetlenebilir. Eşanlı denklem sisteminin tahmin edilmesi için literatür tarafından çok fazla yöntem önerilmesine rağmen her bir yöntem farklı ekonometrik problemlerin varlığı halinde tercih edilmelidir. Tüm modellerin logaritmaları alınmış olup bazı denklemlerde sonuç anlamlı olmadığı için eşanlı model tahmini doğrusal koşulmuştur.

Eşanlı modeller nihai olarak 2 aşamalı GMM ile tahmin edilerek sonuçları Çizelge 2'de sunulmuştur. $\mathrm{Bu}$ yöntem ile elde edilen sonuçlar GİR, DEKK, 2- 
EKK, 3-EKK'deki tahmin yöntemleri ile elde edilen sonuçların sahip olduğu ekonometrik problemlere sahip değildir. Kısaca bu yöntem hem modeller arası hataların ilişkili olmasını dikkate alırken hem de içsel değişkenleri dikkate alarak eşanlı olarak modellerin tahmini gerçekleştirilebilmektedir. Yöntemin başka bir üstünlüğü ise 2-EKK ve 3 -EKK yönteminde her denklem için aynı araç-dışsal değişkenler kullanma zorunluluğu varken 2 aşamalı GMM yönteminde ise farklı modellerde farklı araç değişken kullanma esnekliği mevcuttur ${ }^{4}$.
Ayrıca parametre tahminlerine ilişkin standart hatalar hem değişen varyansa hem de otokorelasyona karşı güçlüdür. Qureshi et al. (2016) GMM yöntemini kullandıkları çalışmalarında modeli logaritmik olarak tahmin etmişlerdir. Bu çalışmada ise modellerdeki bazı denklemlerde logaritmik olarak anlamlı olmadığı için GMM ile tahminde logaritmik model kullanılmamıştır.

Çizelge 2'deki sonuçlar incelendiğinde açıklayıcı tüm değişkenlerin işaretleri ekonomik teori ile uyumlu ve istatistiksel olarak anlamlıdır.

Çizelge 2. İki aşamalı GMM tahmin sonuçları

\begin{tabular}{|c|c|c|c|c|c|}
\hline \multicolumn{3}{|l|}{ Üretim denklemi } & \multicolumn{3}{|c|}{$\Delta$ Tüketim denklemi } \\
\hline Değişken & Katsayı & Standart hata & Değişken & Katsayı & $\begin{array}{l}\text { Standart } \\
\text { hata }\end{array}$ \\
\hline buğday fiyatı (-1) & $62.47^{\mathrm{a}}$ & 25.79 & buğday fiyatı & $-0.0002^{c}$ & 0.0001 \\
\hline buğday üretimi (-1) & $0.288^{\mathrm{a}}$ & 0.085 & $\Delta$ kişi başı gelir & $-0.00006^{b}$ & 0.00003 \\
\hline TMO alım miktarı & $0.449^{a}$ & 0.146 & Sabit & $0.0277^{\mathrm{c}}$ & 0.0167 \\
\hline misır fiyatı $(-1)$ & $-31.27 \mathrm{a}$ & 11.23 & & & \\
\hline kukla değişken & $4048.00^{\mathrm{a}}$ & 718.89 & & & \\
\hline sabit & 1684.22 & 2757.74 & & & \\
\hline
\end{tabular}

\begin{tabular}{lll}
\hline İthalat denklemi & & \\
\hline & & \\
Değişken & Katsayı & standart hata \\
\hline üretim/tüketim & $-3451.02^{\text {a }}$ & 370.45 \\
stok & $-0.581^{\mathrm{a}}$ & 0.071 \\
sabit & $6573.75^{\mathrm{a}}$ & 621.85 \\
\hline
\end{tabular}

\section{Fiyat denklemi}

\begin{tabular}{lll}
\hline Değişken & Katsayı & Standart hata \\
\hline stok & $-0.004^{\mathrm{a}}$ & 0.0007 \\
gübre ithal fiyatı & $0.069^{\mathrm{a}}$ & 0.021 \\
ihracat miktarı & $0.011^{\mathrm{a}}$ & 0.004 \\
sabit & $114.72^{\mathrm{a}}$ & 6.21 \\
\hline
\end{tabular}

\begin{tabular}{lll}
\hline İhracat denklemi & & \\
\hline Değişken & Katsayı & $\begin{array}{l}\text { Standart } \\
\text { hata }\end{array}$ \\
\hline buğday üretimi & $0.129^{\mathrm{a}}$ & 0.024 \\
Stok & $0.211^{\mathrm{a}}$ & 0.082 \\
dolar kuru & $-342.74^{\mathrm{b}}$ & 149.22 \\
Sabit & $-1416.39^{\mathrm{a}}$ & 334.24 \\
\hline \hline & & Olasılık \\
Test & Test değeri & değeri \\
\hline Hansen J testi & 7.68186 & 0.9052 \\
& & \\
& & \\
& & \\
\hline
\end{tabular}

Notlar: (1): a,b,c; sirasıyla ilgili test istatistiğinin \%1, \%5 ve $\% 10$ önem seviyesinde ret edildiğini göstermektedir.(2): (-1): bir dönem gecikmeyi, $\Delta$ : birinci farkı ifade etmektedir.(3): parasal değerler reel $\$$, miktar değerleri ise bin ton'dur.

Buğday modeli incelendiğinde; bir önceki yıl buğday üretici fiyatının $1 \$$ artması buğday üretimini 62 bin ton artırmaktadır. İkame ürün olarak bir önceki yıl misır üretici fiyatının $1 \$$ artması ise buğday üretimini 31 bin ton azaltmaktadır. Bir önceki yllki buğday üretiminin ise cari yıla \%29'luk bir artırıcı etkisi bulunurken TMO alım miktarının ise \% $45^{\prime}$ lik bir etkisi bulunmaktadır.

Elde edilebilen mevcut değişkenler arasında buğday tüketimi üzerinde sadece kişi başı gelir ve buğday

${ }^{4} \mathrm{Bu}$ kapsamda üretim ve ithalat modellerinde sadece modelde yer alan değişkenler, tüketim modelinde stok, üretim/tüketim, dolarkuru, gübre ithal fiyatı; ihracat modelinde buğday fiyatı (-1), TMO alım miktarı, mısır fiyatı (1), üretici fiyatı etkili bulunmuştur. Buğday fiyatının $1 \$$ artması bu ürünün tüketimini yaklaşı $200 \mathrm{~kg}$ azaltmaktadır. Kişi başı gelirin buğday tüketimini azaltması sürpriz değildir. Çünkü tüketicilerin harcanabilir gelirinin artması buğdaya nazaran kalori olarak daha zengin ve daha lüks gıda ürünleri tüketmesine yöneltmektedir. Bu kapsamda kişi başı gelirin $1 \$$ artması buğday tüketimini $60 \quad \mathrm{~kg}$ azaltmaktadır.

İthalat denklemine bakıldığında; üretimin tüketimi

buğday üretimi (-1), üretim/tüketim, gübre ithal fiyatı; fiyat modelinde ise buğday fiyatı(-1), TMO alımmiktarı, mısır fiyatı $(-1)$, buğday üretimi $(-1)$, üretim/tüketim, dolarkuru, kişibaşı gelir değişkenleri araç olarak kullanılmıştır. 
karşılama oranındaki 1 katlık bir artış ithalat miktarını yaklaşık 3.5 milyon ton azaltırken, stok miktarı ise \%58'lik bir azaltıcı etki yapmaktadır. İhracat denklemi incelendiğinde; ihracat miktarı üzerinde buğday üretimi \%13'lük artırıcı bir etki yaparken stok miktarı ise \%21'lik artırıcı bir etki yapmaktadır. Buğday üretiminde en önemli girdilerden birinin motorin fiyatı olduğu düşünüldüğünde dolar kurundaki artışın ihracatı azaltması sürpriz değildir. Bu kapsamda dolar kurundaki 1 TL'lik bir artış ihracat miktarını yaklaşık 340 bin ton azaltmaktadir.

Son olarak fiyat denklemi incelendiğinde; yaklaşık 1 tonluk bir stok artışının buğday fiyatını ton başına 4 dolar azaltirken ihracat miktarı 11 dolar artırmaktadır. Gübre ithal fiyatı ise buğday fiyatı üzerinde yaklaşık \%7'lik artırıcı bir etkiye sahiptir.

Modellerde kullanılan araç değişkenlerin uygunluğunu sinayan Hansen (1982) tarafindan önerilen J test istatistiği ret edilememiştir. Dolayısıyla model kapsamında kullanılan araç değişkenler uygundur.

\section{SONUÇ ve ÖNERILER}

Litaratür çalışmaları incelendiğinde buğday sektörünün farklı yönlerini dikkate alan çok sayıda ekonometrik çalışmalara rastlanmaktadır. Bu çalışma literatürdeki diğer çalışmalardan farklı olarak, zaman serisi problemlerine güncel gelişmeler eşliğinde ayrıntılı olarak temas etmesi ve eşanlı denklem tahmin yöntemleri kullanılarak her bir yöntemin hangi problemleri nasıl çözeceğini göstermesi yönünden farklıdır. Denklem sayısının fazla olması ve veri zaman aralığının uzun tutulması da diğer çalışmalardan farkını ortaya koymaktadır.

GMM sonuçlarına göre buğday üretimini etkileyen değişkenler; bir önceki yıl buğday üretimi, bir önceki yıl buğday üretici fiyatı, Toprak Mahsülleri Ofisi tarafindan yapılan alım miktarı ve bir önceki yıl mısır üretici fiyatıdır. Buğday tüketimini etkileyen değişkenler; buğday fiyatı ve kişi başı gelirdir. Buğday ithalatını etkileyen değişkenler; üretimin tüketimi karşılama oranı ve stok miktarıdır. Buğday ihracatını etkiyen değişkenler; buğday üretimi, stok ve dolar kurudur. Buğday fiyatını etkileyen değişkenler; stok, gübre ithal fiyatı ve ihracattır.

Buğday üretimi modelinde bir önceki yıl buğday üretici fiyatı, bir önceki yıl buğday üretimi ve TMO alım miktarı üretime pozitif etki yaparken bir önceki yıl mısır fiyatı üretime negatif etki yapmaktadır. Buğday tüketim modelinde buğday fiyatı ve kişi başı gelir tüketime negatif etki yapmakta olup, kişi başı gelirin tüketimi azaltma nedeni insanların geliri arttıkça daha lüks gıda mallarına yönelmesi olarak açlklanabilir. Ithalat modelinde üretimin tüketimi karşılama oranı ve stoklar ithalata negatif etki yapmaktadır. İhracat modelinde buğday üretimi ve stok ihracata pozitif dolar kuru ise ihracata negatif etki yapmaktadır. Buğday fiyat modelinde gübre ithal fiyatı ve ihracat miktarı fiyata pozitif etki yaparken stok negatif etki yapmaktadır.

Modelden elde edilen sonuçlara göre üretim denkleminde TMO alım miktarı pozitif yönde etkiye sahip olduğundan, devletin üretim miktarının yüksek olmasının istediği dönemlerde TMO alım miktarlarının artırmasının gerektiği önerilmektedir. İhracat denkleminde ise dolar kurunun negatif yönde etkili olduğu görülmektedir. Bunun sebepleri de girdi maliyetlerinden en önemlisi olan yakıt fiyatların göreli fiyat hareketlerinin olduğundan, bu nedenle özellikle ekim dönemlerinde çiftçiye mazot desteğinin yanı sıra düşük fiyattan sabit kur ile yakıt sağlanabilir. Fiyat denkleminde gübre ithal fiyatının pozitif yönde etkilediği gözlemlenmektedir. Gübre ithal fiyatının artışı buğday fiyatını artırırken üreticinin maliyetini yükseltmekte tüketicinin de tüketim talebini azalttığından, yerli gübre imalatına ağırlık verilmesi veya gübre desteğinin yapılması dikkate alınmalıdır.

$\mathrm{Bu}$ çalışmada her ne kadar ulaşılan nihai model yukarıdaki model olsa da model tahmin süreci kapsamında çok fazla değişken ve bu değişkenlerin farklı varyasyonları ve değişkenlere bağlı olarak farklı zaman dilimleri denenerek yüzlerce model tahmini gerçekleştirilmiştir. Böylece geniş bir zaman aralığ analiz edilerek buğday arz ve talep modellerinde hangi değişkenlerin ekonomik teori ve istatistiksel açıdan uygun olduğunun tespiti yapılmıştır. Bu tespit tarım ekonomisi araştırmacıları için değerli bulgular sağlamıştır.

\section{KAYNAKLAR}

Adanacıŏ̆lu H, Engindeniz S 2011. Tarımsal Üretimde Etkili Olan Faktörlerin Analitik Yaklaşımla İncelenmesi: Buğday Örneği, TKB Türk tarım Dergisi, 200: 20-28

Akay AŞ 2005. Türkiye Ekonomisinde Buğday ve Buğday Türevlerinin Analizi, Yüksek Lisans Tezi, Akdeniz Üniversitesi Sosyal Bilimler Enstitüsü

Aykanat S 2009. Buğday Tarımında Farklı Toprak İşleme Yöntemlerinin Teknik ve Ekonomik Yönden Karşılaştırılması, Yüksek Lisans Tezi, Çukurova Üniversitesi Fen Bilimleri Enstitüsü

Dawson GH 2016. AB Buğday İhracatı Pazararının Fiyatlandırma Analizi Journal of Agricultural Economics, Volume 68, İssue 1 February 2017, Pages 301-315

Demir O 2012. Avrupa Birliği Tam Üyeliğinin Türkiye Buğday Sektörüne Bölgesel Etkilerinin Analizi. Atatürk Ünv. Fen Bilimleri Ens. Doktora Tezi. Erzurum.

Dickey DA, Fuller WA 1979. "Distribution of The Estimators For Autoregressive Time Series With A Unitroot", Journal of The American Statistical Association, 74, 427-431 
FAO 2017. Food and Agriculture Organisation Web Page http://www.fao.org/faostat/en/\#data/QC (Erişim 12.06.2017).

Hansen LP 1982. Large Sample Properties of Generalized Method of Moments Estimators. Econometrica 50: 1029-1054.

Nerlove M 1956. Estimates of the Elasticities of Supply of Selected Agricultural Commodities, Journal of Farm Economics, 38: 496-509.

Oğuz C, Arısoy H 2005. Tarımsal Araştırma Enstitüleri Tarafindan Yeni Geliştirilen Buğday Çeşitlerinin Tarım İşletmelerinde Kullanım Düzeyi Ve Geleneksel Çeşitler İle Karşılaştırmalı Ekonomik Analizi -Konya İli Örneği, TEAE, Ankara

Özcan H, Bayramoğlu HO, Aydın A 2009. Buğday Tarımı.

http://www.ktae.org/gunceluyg/bugday.htm (Erişim tarihi: 15..05. 2017).
Perron P, 1989. The Great Crash, the Oil Price Shock, and the Unit Root Hypothesis, Econometrica, 57(6): 1361-1401.

Perron P 1997. Further Evidence on Breaking Trend Functions in Macroeconomic Variables, Journal of Econometrics, 80(2): 355-385.

Qureshi M, Awan I, Arshad U, Rasli Z, Zaman AM, Khan F 2016. Dynamic Linkages Among Energy Consumption, Airpollution, Green House Gas Emission Sand Agricultural Production In Pakistan: Sustainable Agriculture Key to Policy Success. Natural Hazards, 84(1): 367-381.

Sepetoğlu H 2006. Tarla Bitkileri 1 (Tarla Tarımı, Tahillar, Yemeklik Tane Baklagiller), Ege Üniversitesi, İzmir.

Zivot E, Andrews D 1992. Further Evidence On The Great Crash, The Oil Price Shock, and The Unit Root Hypothesis. Journal of Business \&Economic Statistics, 10(3): 251-270. 